\title{
Thin-Layer Chromatographic Separation of 6-Iodo-2-Methylthio-3-Alkyl(Aryl)-4-Quinazolones
}

\author{
M. N. Sharma / M. R. Chaurasia* \\ Department of Chemistry, Banaras Hindu University, Varanasi-5, India
}

Although thin-layer chromatographic (TLC) separation of some individual heterocyclic compounds containing nitrogen and sulphur as hetero atom(s) is reported in the literature $[1,2]$, there is nothing concerning 6-iodo2-methylthio-4-quinazolones. We successfully applied TLC to the separation and identification of a few alkyl (aryl) derivatives of 6-iodo-2-methylthio-4-quinazolones, which give practically the same violet colour in U.V. light $(254 \mathrm{~nm})$ and cause no mutual interference with $\mathrm{R}_{\mathrm{f}}$-values.

\section{Procedure}

Glass plates $(20 \mathrm{~cm} \times 20 \mathrm{~cm})$ were coated with silica gel PF 254 (E. Merck) to a thickness of $0.25 \mathrm{~nm}$ and dried at room temperature in the air for $48 \mathrm{hrs}$. The compounds, dissolved in ethanol $(2-3 \mu \mathrm{g} / \mathrm{ml})$ were spotted at $2.0 \mathrm{~cm}$ intervals on the starting line of the plates. The plates were then developed in ascending direction until the solvent front had travelled $14-15 \mathrm{~cm}$. The plates were allowed to dry in air at $32^{\circ} \mathrm{C}$.

\section{Experimental}

Of many solvent systems tried only benzene and benzene: cyclohexane $(5: 1)$ were found suitable for good separation.

\footnotetext{
* Present address: Department of Chemistry, D.A.V. College, Dehradun, India
}

U.V. light ( $254 \mathrm{~nm}$ ) was used for visualization of the spots. Results were reproducible.<smiles>[R]n1c(SC)nc2ccc(I)cc2c1=O</smiles>

\begin{tabular}{|c|c|c|c|}
\hline \multirow{2}{*}{ S.No. } & \multirow{2}{*}{$\mathbf{R}$} & \multicolumn{2}{|r|}{$\mathbf{R}_{\mathbf{f}}$} \\
\hline & & benzene & benzene: cyclohexane (5:1) \\
\hline 1. & Methyl & 0.54 & 0.38 \\
\hline 2. & Ethyl & 0.61 & 0.47 \\
\hline 3. & Phenyl & 0.55 & 0.35 \\
\hline 4. & o-Tolyl & 0.585 & 0.42 \\
\hline 5. & m-Tolyl & 0.59 & 0.41 \\
\hline 6. & p-Tolyl & 0.58 & 0.40 \\
\hline 7. & p-Anisyl & 0.39 & 0.23 \\
\hline 8. & p-Phenetyl & 0.45 & 0.27 \\
\hline 9. & p-Bromophenyl & 0.77 & 0.608 \\
\hline
\end{tabular}

\section{Acknowledgement}

Authors wish to thank Prof. G. B. Singh, Head of the Department of Chemistry for providing necessary facilities and one of them (M.N.S.) thanks to C.S.I.R., New Delhi for financial help.

\section{References}

[1] G. C. Barrett and A. R. Khokhar, J. Chromatog. 39, 47 (1969).

[2] B. V. Unkovskii and L. A. Ignatova, Khim. Geterotsikl. Socdin 897 (1969). 